\title{
Research on the thermal hazard of N-Nitrodihydroxyethyl dinitrate (DINA) under the action of diethanolamine
}

\author{
Yuehua Li ${ }^{1}$, Yu Liu ${ }^{1,2}$, Liping Chen ${ }^{1,}{ }^{*}$, Wenqian $W^{1}$, Xiaoqiao Zhao ${ }^{1}$, Wanghua Chen ${ }^{1}$ \\ ${ }^{1}$ Department of Safety Engineering, School of Chemical Engineering, Nanjing University of Science and Technology, Nanjing Jiangsu \\ 210094, China \\ 2 Shanxi Applied Physics-Chemistry Research Institute, Xi'an 710065, China
}

\begin{abstract}
N-Nitrodihydroxyethyl dinitrate (DINA) is a commonly used energetic material. In this work, the effect of diethanolamine (DEA) on the thermal stability of DINA was studied. Firstly, the decomposition kinetics of DINA under the influence of DEA was analyzed by applying dynamic differential scanning calorimeter (DSC) experiments. Then, isothermal DSC tests with the "Interruption and re-scanning" method determined that the decomposition reactions of DINA containing 29\% DEA consists of four continuous steps: the first step is a n-order reaction, and the last three steps are autocatalytic reactions. The kinetic parameters of the four-step reaction model were calculated by model-fitting method. Finally, the thermal risk parameter like TMRad was predicted based on the kinetic parameters, which has certain guiding significance for the process production of DINA.
\end{abstract}

\section{Introduction}

N-Nitrodihydroxyethyl dinitrate, commonly known as DINA (see Fig.1 for its molecular structure), is a chemical product with high energy and sensitivity, which will decompose at high temperature, accompanied by rapid gas and heat production [1-3]. It is mainly used as a high energy plasticizer in propellants or as a gelling agent in the preparation of nitrocellulose [4,5]. As an energetic material that appeared late, DINA is indispensable in the field of national defense, but currently there are few literatures available for research on DINA.<smiles>O=[N+]([O-])OCCN(CCO[N+](=O)[O-])[N+](=O)[O-]</smiles>

Figure 1 Molecular structure of DINA.

One of the aspects of DINA research is its application. The main work carried out in this area is the research on the effect of DINA on the performance (including combustion performance) of the double-base propellants $[5,6]$.

In addition, some scholars are concerned about the thermal safety of DINA itself and products containing DINA. For example, thermal stability of DINA is a direction of concern before the application. The relevant literature believes that the melting point of DINA is $49.5^{\circ} \mathrm{C}$ $-51.5^{\circ} \mathrm{C}$, it starts to decompose significantly at $160 \mathrm{oC}$, and the Abel test value reaches $60 \mathrm{~min}$ at $72^{\circ} \mathrm{C}[6,7]$. Therefore,
DB propellants containing DINA can be processed at relatively high temperatures [8]. In terms of the thermal stability of DINA itself, Zhang Jun et al. [9] have mainly studied the characteristics and kinetics of the thermal decomposition of DINA. In addition, related scholars from Xi'an Institute of Modern Chemistry have studied the thermal safety of intermediates in the synthesis of DINA [4].

Current research on the thermal stability of energetic materials often focuses on the energetic materials itself and the thermal safety issues in the application process. However, the thermal stability of energetic materials in the synthesis process cannot be ignored, especially when the synthesis often involves strong acids such as nitric acid, sulfuric acid, hydrochloric acid, and alkaline substances such as sodium carbonate and sodium hydroxide, because these substances can easily catalyze the decomposition of high energy substances. There are also many chemicals involved in the synthesis of DINA.

In this work, the purpose is to understand the related substances that have a greater impact on the thermal stability of DINA by the nitric acid/magnesium oxide $\left(\mathrm{HNO}_{3} / \mathrm{MgO}\right)$ approach. On this basis, to further grasp the thermal risk parameters of the less stable mixtures. At first, the reactant and its percentage that have the greatest influence on the decomposition of DINA were determined by DSC screening tests. Then, the thermal decomposition parameters were obtained by dynamic DSC. Finally, thermal risk parameters were predicted by numerical simulations. These research results have an important guiding role in the safe production of DINA. 


\section{Experiment sections}

\subsection{The nitric acid/magnesium oxide $\left(\mathrm{HNO}_{3} / \mathrm{MgO}\right)$ approach}

There are two main approaches for the synthesis of DINA: the nitric acid/acetic anhydride $\left(\mathrm{HNO}_{3} / \mathrm{Ac}_{2} \mathrm{O}\right)$ approach and the nitric acid/magnesium oxide $\left(\mathrm{HNO}_{3} / \mathrm{MgO}\right)$ approach [10]. The general equation of the latter is shown in Fig. 2.

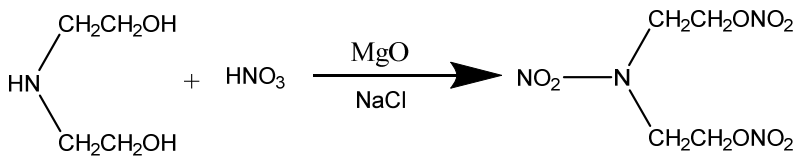

Figure 2 Reaction equation of DINA synthesis by the nitric acid/magnesium oxide $\left(\mathrm{HNO}_{3} / \mathrm{MgO}\right)$ approach

The reactants included in the nitric acid/magnesium oxide $\left(\mathrm{HNO}_{3} / \mathrm{MgO}\right)$ approach are fuming nitric acid $\left(\mathrm{HNO}_{3}\right)$, magnesium oxide $(\mathrm{MgO})$, diethanolamine (DEA), and sodium chloride $(\mathrm{NaCl})$. The reaction temperature of this process is $60^{\circ} \mathrm{C}-65^{\circ} \mathrm{C}[11,12]$.

\subsection{Samples}

DINA used in the experiment were white crystals, purchased from Qingyang Chemical Plant in Liaoning. Diethanolamine (99\% purity) was purchased from Myrel Chemical Technology Corporation, Shanghai. Fuming nitric acid $(\geqslant 97.2 \%)$ was purchased from Sinopharm Chemical Reagent Company. Magnesium oxide (99\%) and sodium chloride $(99.8 \%$ ) were purchased from Juyou Scientific Equipment Corporation, Nanjing. All of the chemicals were used without further purification.

\subsection{Differential Scanning Calorimeter DSC}

Differential scanning calorimeter DSC 1 was manufactured by Swiss METTLER TOLEDO. The samples were sealed in steel high-pressure crucibles $(30 \mu$ L) with gold-plated pads. For dynamic tests, the heating rates were $1^{\circ} \mathrm{C} / \mathrm{min}, 2^{\circ} \mathrm{C} / \mathrm{min}, 4^{\circ} \mathrm{C} / \mathrm{min}, 10^{\circ} \mathrm{C} / \mathrm{min}$, the temperature range was $30^{\circ} \mathrm{C}-400^{\circ} \mathrm{C}$. For isothermal tests, $105^{\circ} \mathrm{C}$ and $115^{\circ} \mathrm{C}$ were selected as the test temperatures. The "Interruption and re-scanning" method selected $180^{\circ} \mathrm{C}$ for testing, and the heating rate was $8^{\circ} \mathrm{C} / \mathrm{min}$. All of the DSC tests were conducted under a $\mathrm{N}_{2}$ atmosphere.

\section{Results and discussion}

\subsection{DSC test}

\subsubsection{DSC screening test of the related reactants}

In the synthesis process, each reactant inevitably contacts the product DINA, which may affect the stability of DINA. These substances include $\mathrm{HNO}_{3}, \mathrm{MgO}, \mathrm{DEA}$ and $\mathrm{NaCl}$. The dynamic DSC screening results with a heating rate of $8^{\circ} \mathrm{C} / \mathrm{min}$ are shown in Table 1 and Fig.4. The decomposition of DINA in the dynamic DSC test contains four consecutive exothermic peaks (P1-P4) (see Fig.3), which is consistent with the conclusion of the literature [9]. The $\mathrm{P} 2$ is the main peak, and the $\mathrm{P} 1, \mathrm{P} 3$, and $\mathrm{P} 4$ are not obvious, so the peak temperature of $\mathrm{P} 2$ is used as $\mathrm{T}_{\mathrm{p}}$ in Table 1.

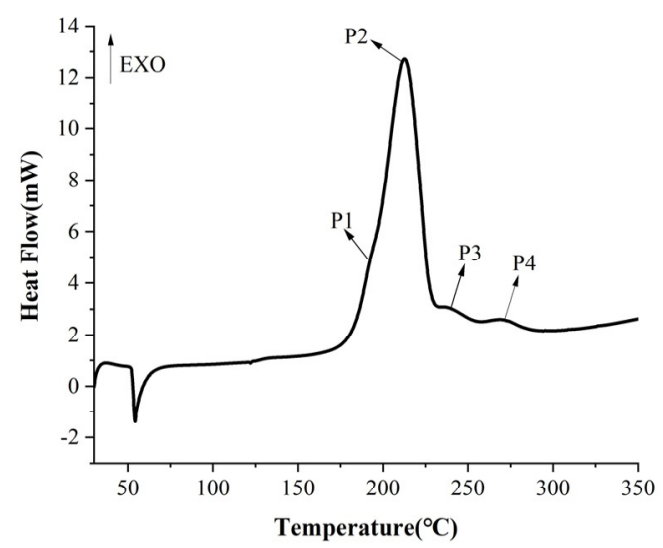

Figure.3 DSC curve of DINA at $8^{\circ} \mathrm{C} / \mathrm{min}$

Table 1. DSC screening test results for related reactants

\begin{tabular}{cccccc}
\hline Samples & $\begin{array}{c}m_{1} \\
(\mathrm{mg})\end{array}$ & $m_{2}(\mathrm{mg})$ & $T_{0}\left({ }^{\circ} \mathrm{C}\right)$ & $T_{\mathrm{p}}\left({ }^{\circ} \mathrm{C}\right)$ & $Q(\mathrm{~J} / \mathrm{g})$ \\
\hline DINA & 0.88 & 0 & 160.22 & 211.09 & -2846.36 \\
$\begin{array}{c}\text { DINA+M } \\
\text { gO }\end{array}$ & 0.89 & 0.11 & 165.42 & 211.49 & -2858.49 \\
$\begin{array}{c}\text { DINA+D } \\
\text { EA }\end{array}$ & 0.90 & 0.09 & 116.46 & 208.33 & -2853.34 \\
$\begin{array}{c}\text { DINA+Na } \\
\text { C }\end{array}$ & 0.90 & 0.10 & 158.66 & 210.12 & -2866.26 \\
$\begin{array}{c}\text { DINA+H } \\
\mathrm{NO}_{3}\end{array}$ & 0.91 & 0.09 & 156.38 & 208.89 & -2823.39 \\
\hline
\end{tabular}

Note: $m_{1}$ is the mass of DINA, $m_{2}$ is the mass of related reactants, $T_{0}$ is the onset temperature (the temperature at which the exothermic peak deviates from the baseline), $T_{\mathrm{p}}$ is the peak temperature of $\mathrm{P} 2, Q$ is the specific heat release.

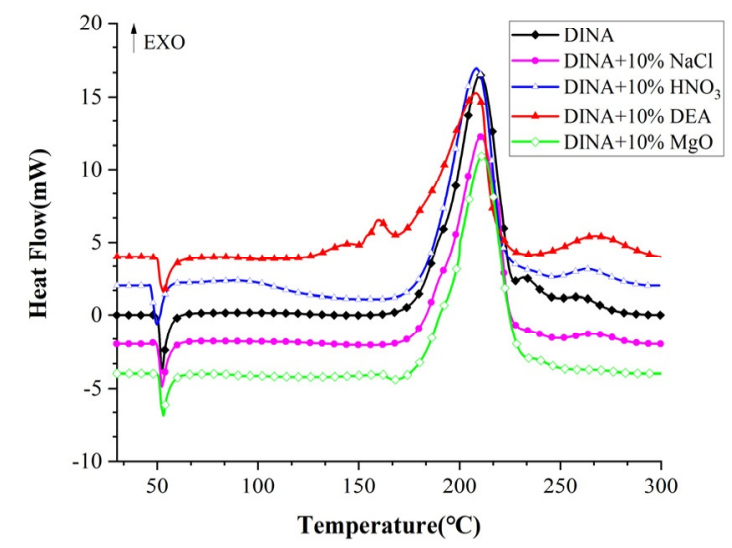

Figure.4 DSC test of DINA mixed with related raw materials at $8^{\circ} \mathrm{C} / \mathrm{min}$

It can be seen from Table 1 that the onset decomposition temperature of pure DINA is $160^{\circ} \mathrm{C}$. Among the above four chemicals, DINA containing 10\% DEA has the lowest onset decomposition temperature of $116^{\circ} \mathrm{C}$. The onset decomposition temperature range of 
DINA containing three other chemicals is between $155^{\circ} \mathrm{C}$ and $165^{\circ} \mathrm{C}$, which is close to the onset decomposition temperature of the exothermic peak of pure DINA.

In addition, $\mathrm{MgO}, \mathrm{NaCl}$ and $\mathrm{HNO}_{3}$ have little effect on the peak shape of DINA decomposition peaks. When DEA was added, a small exothermic peak appeared in front of the original exothermic peak of DINA. At the same time, the exothermic peak P3 that originally existed in the form of a shoulder peak after the main exothermic peak P2 disappeared, and only one exothermic peak appeared at the position of $\mathrm{P} 4$, which indicates that DEA may affect the decomposition process of DINA.

The above analysis results show that DEA has the largest impact on the decomposition of DINA compared to other chemicals.

\subsubsection{DSC screening test of DEA with different contents}

In this part, DINA with different contents of DEA were screened by dynamic DSC to determine the content of DEA that had the greatest effect on the decomposition of DINA. The test sample mass and results are shown in Table 2 and Fig. 5.

Table 2 DSC results of DEA samples with different contents

\begin{tabular}{ccccc}
\hline Samples & $m_{1}(\mathrm{mg})$ & $m_{3}(\mathrm{mg})$ & $T_{0}\left({ }^{\circ} \mathrm{C}\right)$ & $Q(\mathrm{~J} / \mathrm{g})$ \\
\hline DINA & 0.90 & & 160.22 & -2846.36 \\
DEA & & 0.91 & 110.12 & -66.74 \\
DINA+2\%DEA & 0.88 & 0.02 & 140.49 & -2790.48 \\
DINA+9\%DEA & 0.91 & 0.09 & 116.65 & -2596.85 \\
DINA+19\%DEA & 0.88 & 0.22 & 114.33 & -2318.63 \\
DINA+29\%DEA & 0.89 & 0.37 & 104.26 & -2040.25 \\
DINA+35\%DEA & 0.88 & 0.49 & 109.29 & -1873.69 \\
DINA+42\%DEA & 0.88 & 0.65 & 110.58 & -1678.85
\end{tabular}

Note: $m_{1}$ is the mass of DINA, $m_{3}$ is the mass of DEA, $T_{0}$ is the onset temperature (the temperature at which the exothermic peak deviates from the baseline), $Q$ is the specific heat release.
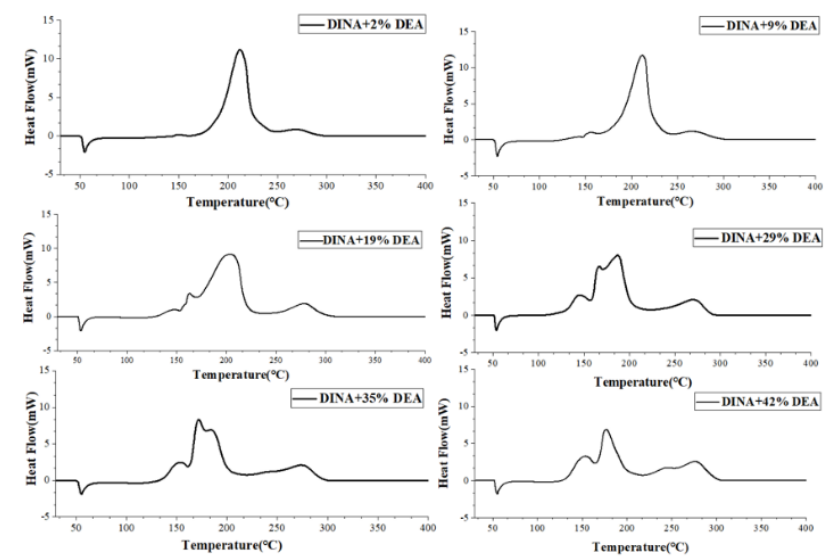

Figure.5 Dynamic DSC results of DINA + DEA with different contents at $8^{\circ} \mathrm{C} / \mathrm{min}$

From Table 2, the onset temperature of DEA is $110^{\circ} \mathrm{C}$, and the specific heat release is $66 \mathrm{~J} / \mathrm{g}$. DINA is relatively unstable and has high decomposition energy. As the content of DEA increases, the specific heat release of the mixture gradually decreases.

From Table 2 and Fig.5, one can see that the onset decomposition temperature of the mixture gradually decreases and then increases with the increase of DEA content. When the DEA content was $29 \%$, the onset temperature was reduced to a minimum of $104^{\circ} \mathrm{C}$. Therefore, DINA containing 29\% DEA was selected as a typical sample, and the thermal decomposition kinetics and thermal stability of this sample were further studied.

\subsubsection{Dynamic DSC test}

When there are multiple exothermic peaks in DSC tests, considering that the decomposition at low temperatures is more likely to occur than reactions at higher temperatures, and the former may be the triggering conditions of the latter. So, for the DINA containing 29\% DEA, here mainly focus on the first three exothermic peaks. The test results are shown in Table 3 and Fig.6. With the increasing of the heating rate, the onset temperature and peak temperature of the exothermic peaks gradually increase, and the average specific heat release of the first three peaks in the four tests is $1520 \pm 58 \mathrm{~J} / \mathrm{g}$.

Table 3 Dynamic DSC results of the first 3 exothermic peaks of DINA $+29 \%$ DEA

\begin{tabular}{lllll}
\hline$\beta\left({ }^{\circ} \mathrm{C} / \mathrm{min}\right)$ & $m_{1}(\mathrm{mg})$ & $m_{3}(\mathrm{mg})$ & $T_{0}\left({ }^{\circ} \mathrm{C}\right)$ & $Q(\mathrm{~J} / \mathrm{g})$ \\
\hline 1 & 0.89 & 0.37 & 91.24 & -1443.39 \\
2 & 0.92 & 0.39 & 98.36 & -1561.56 \\
4 & 0.90 & 0.38 & 102.29 & -1567.42 \\
10 & 0.89 & 0.37 & 120.67 & -1509.46 \\
\hline
\end{tabular}

Note: $\beta$ is the heating rate, $m_{1}$ is the mass of DINA, $m_{3}$ is the mass of DEA, $T_{0}$ is the onset temperature (the temperature at which the exothermic peak deviates from the baseline), $Q$ is the specific heat release.

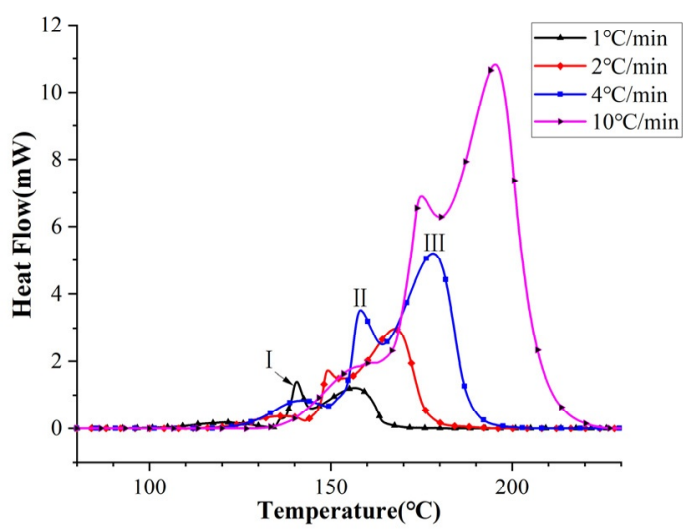

Figure.6 DSC test curve for the first 3 peaks of DINA $+29 \%$ DEA

\subsubsection{Isothermal DSC tests}

Scholars generally believe that isothermal calorimetry experiment is a reliable way for characterizing autocatalytic reactions [13-17]. The results are shown in Table 4 and Fig.7. 
Table 4 Isothermal DSC test results

\begin{tabular}{cccc}
\hline $\begin{array}{c}\text { Isothermal } \\
\text { temperature }\left({ }^{\circ} \mathrm{C}\right)\end{array}$ & $m_{1}(\mathrm{mg})$ & $m_{3}(\mathrm{mg})$ & $Q(\mathrm{~J} / \mathrm{g})$ \\
\hline 105 & 1.00 & 0.41 & -405.13 \\
\hline
\end{tabular}

Note: $m_{1}$ is the mass of DINA. $m_{3}$ is the mass of DEA. $Q$ is the specific heat release.

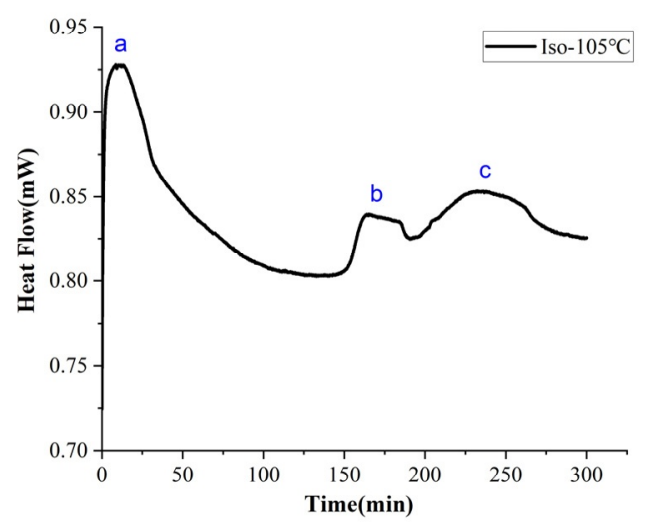

Figure.7 Isothermal test curve of DINA + 29\% DEA

From Fig.7, there are three exothermic peaks at two different isothermal temperatures, which are marked with $\mathbf{a}, \mathbf{b}$, and $\mathbf{c}$. At the beginning of the isothermal test, the heat flow curve corresponding to the peak a directly decreased from the maximum value, which is in line with the isothermal reaction characteristics of n-order chemical reaction model. Subsequently, the heat flow profile of the two exothermic peaks $\mathbf{b}$ and $\mathbf{c}$ show a tendency of bellshaped, indicating that peak $\mathrm{b}$ and peak $\mathrm{c}$ both have the characteristics of autocatalytic reaction.

It can be seen from Table 4 that there is a certain difference in the specific heat release of the isothermal experiment at two different temperatures. The reason is because at higher temperature, other secondary reactions are triggered. In addition, the specific heat releases of the sample in the isothermal tests are less than that in the dynamic DSC (Table 3), so the dynamic DSC test of $10^{\circ} \mathrm{C} / \mathrm{min}$ was done immediately after the $105^{\circ} \mathrm{C}$ isothermal test was completed. The results are shown in Fig.8. Obviously, the sample still has two exothermic peaks after the isothermal experiment, the peak position (peak temperature: $283^{\circ} \mathrm{C}$, peak range: $220-310^{\circ} \mathrm{C}$ ) and peak shape of the latter exothermic peak are consistent with the last exothermic peak in the dynamic DSC curve of the sample (see the graph of DINA+29\%DEA in Fig.5). Therefore, it can be judged that the first exothermic peak still belongs to the "first three exothermic peaks" of the studied sample. And from the dynamic DSC curve of $1^{\circ} \mathrm{C} / \mathrm{min}$ (Refer to Fig.9), it can be clearly seen that there is also a tiny shoulder peak between the exothermic peak I and peak II defined before (the circled part), when the heating rate increases, it is shielded. Therefore, the "top 3" exothermic peaks in the dynamic DSC curve are actually composed of 4 exothermic processes (1-4 in Fig.9). Among them, the three exothermic peaks $\mathbf{a}, \mathbf{b}$, and $\mathbf{c}$ in the isothermal experiment (Fig.7) correspond to the exothermic peaks 1, 2, and 3 in Fig.9, respectively. The peak III in Fig.6 and the first exothermic peak in Fig.8 correspond to the exothermic peak 4 in Fig.9.

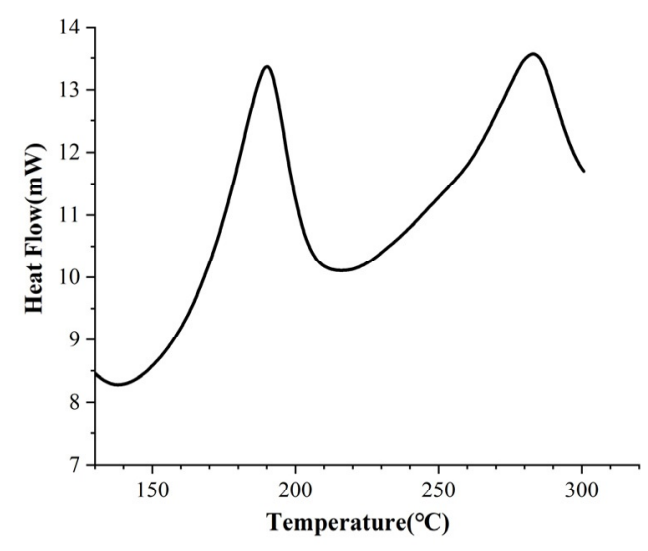

Figure.8 Dynamic DSC test curve of DINA + 29\% DEA after isothermal $115^{\circ} \mathrm{C}$

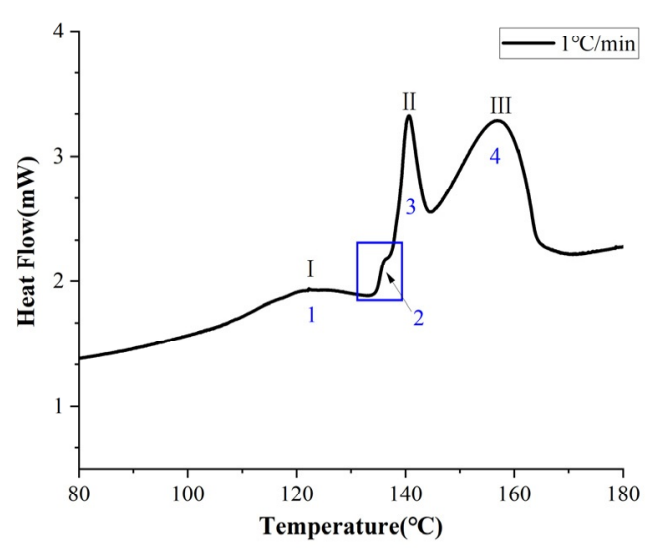

Figure.9 DSC curve of DINA $+29 \%$ DEA at $1{ }^{\circ} \mathrm{C} / \mathrm{min}$

\subsubsection{Interruption and re-scanning method}

The partial decomposition of substances with autocatalytic decomposition characteristics will obviously affect the stability of the entire system [18]. Literature [19] proposed a relatively fast and convenient method for judging the autocatalytic decomposition reaction, namely the "Interruption and re-scanning" method. To determine the reaction model of peak III (or peak 4), $180^{\circ} \mathrm{C}$ was selected as the interruption temperature. The results are shown in Fig. 10.

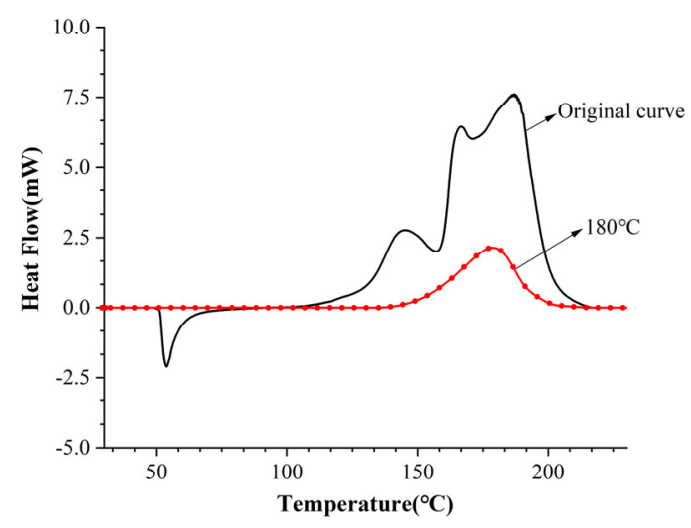

Figure.10 DSC test curves of "Interruption and re-scanning" method 
When the interruption temperature is $180^{\circ} \mathrm{C}$, the retrace curve shows only the peak III, and the $T_{\mathrm{pIII}}$ moves to a lower temperature. Therefore, it can be judged that the peak III has certain autocatalytic properties.

\subsection{Kinetic analysis}

\subsubsection{Kinetic analysis based on Friedman method}

The iso-conversion method is a commonly used kinetic analysis method. The most common differential method for iso-conversion is the Friedman method [20]. Its basic equation is shown in formula (1).

$$
\ln \left(\frac{d \alpha}{d t}\right)_{\alpha, i}=\ln \left[f(\alpha) A_{\alpha}\right]-\frac{E_{\alpha}}{R T_{\alpha, i}}
$$

Where $d \alpha / d t$ is the reaction rate, $\mathrm{s}^{-1} ; \alpha$ is conversion; $A$ is the pre-exponential factor under the reaction conversion $\alpha, \mathrm{s}^{-1} ; f(\alpha)$ is the mechanism function; $E$ is the activation energy, $\mathrm{kJ} / \mathrm{mol} ; R$ is the ideal gas constant, $8.314 \mathrm{~J} /(\mathrm{mol} \cdot \mathrm{K})$; $T$ is temperature, $\mathrm{K}$.

Considering that the calculation results are susceptible to instrument noise and baseline at the beginning and end of the experiment, the data with a conversion rate $\alpha$ between 0.1-0.9 is mainly considered [21]. The results in Fig.11 show that there are multiple changes in the activation energy curve of $\alpha$, and the activation energy fluctuates between $70 \mathrm{~kJ} / \mathrm{mol}$ and $170 \mathrm{~kJ} / \mathrm{mol}$, indicating that the decomposition process cannot be described by a single-step reaction model.

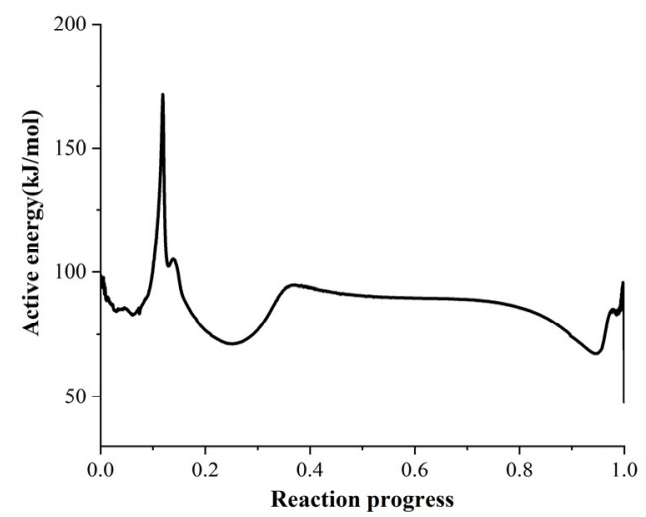

Figure.11 Activation energy vs $\alpha$ for DINA $+29 \%$ DEA

\subsubsection{Model-based fitting method}

Based on the above analysis, it is concluded that the decomposition of DINA containing $29 \%$ DEA is a multistep reaction, the first exothermic decomposition is a norder reaction, the second and third exothermic peaks are autocatalytic reactions, and the fourth exothermic peak also has autocatalytic properties. Therefore, a 4-step continuous reaction (n-order + autocatalytic+ autocatalytic + autocatalytic) model is used to perform a nonlinear fit on the non-isothermal DSC data. The thermal calculation software (TSS) is used for the fitting calculation $[22,23]$. A variety of autocatalytic models have been tried, and finally a kinetic model capable of fitting DINA containing 29\% DEA was determined.

The autocatalytic models used in steps 2 and 4 are universal models of autocatalysis, and the Benito-Perez model used in step 3 is an autocatalytic reaction model with a n-order initiation reaction. The function of reaction rate of the autocatalytic reaction can be described as follows:

Initiation stage $A \stackrel{k_{1}}{\rightarrow} B$

Autocatalytic stage $A+B \stackrel{k_{2}}{\rightarrow} 2 B$

The corresponding reaction model is:

Initiation stage

$$
f(\alpha)=(1-\alpha)^{n}
$$

Autocatalytic stage

$$
f(\alpha)=\alpha^{n 2}(1-\alpha)^{n 1}
$$

Thus, the reaction rate equation is:

$$
\begin{aligned}
& \text { first step }\left(\frac{d \alpha}{d t}\right)_{1}=k_{1}(1-\alpha)^{n} \\
& \text { second step }\left(\frac{d \alpha}{d t}\right)_{2}=k_{2} \alpha^{n 2}(1-\alpha)^{n 1}
\end{aligned}
$$

From this, the total reaction rate of the reaction is expressed as:

$$
\frac{d \alpha}{d t}=k_{1}(1-\alpha)^{n}+k_{2} \alpha^{n 2}(1-\alpha)^{n 1}
$$

As for n-order reaction, reaction model and reaction rate can be described as:

$$
\begin{aligned}
& f(\alpha)=(1-\alpha)^{n} \\
& \frac{d \alpha}{d t}=A \exp (-E / R T)(1-\alpha)^{n}
\end{aligned}
$$

The kinetic fitting results based on the above reaction model are shown in Fig. 12 and Table 5.

Table 5 Kinetic parameters of the reaction model for DINA $+29 \%$ DEA

\begin{tabular}{cccccccccc}
\hline & Model & $\begin{array}{c}\ln A \\
(1 / \mathrm{s})\end{array}$ & $\begin{array}{c}E \\
(\mathrm{~kJ} / \mathrm{mol})\end{array}$ & $n_{1}$ & $n_{2}$ & $\ln \left(Z_{0}\right)$ & $\begin{array}{c}E \mathrm{z} \\
(\mathrm{kJ} / \mathrm{mol})\end{array}$ & $n$ & $\begin{array}{c}Q \\
(\mathrm{~kJ} / \mathrm{kg})\end{array}$ \\
\hline 1 & n-order & 27.73 & 114.65 & - & - & - & - & 1.21 & -122.21 \\
2 & autocatalytic & 32.59 & 115.77 & 1.07 & 1.11 & -2.14 & 0.02 & - & -102.45 \\
3 & n-order & 32.26 & 181.44 & - & - & - & - & 1.69 & -31.92 \\
& & & & & & & & & -312.00 \\
& autocatalytic & 22.16 & 90.90 & 0.80 & 1.67 & - & - & - & -1003.34 \\
& autocatalytic & 18.41 & 86.23 & 0.85 & 0.91 & -0.76 & 3.30 & - &
\end{tabular}

Note: Standard uncertainties $\mathrm{u}$ are $\mathrm{u}(\ln A)=0.36 \mathrm{~s}^{-1}$, $\mathrm{u}(E)=1.68 \mathrm{~kJ} / \mathrm{mol} ; \mathrm{u}(n)=0.014 \mathrm{u}\left(\ln Z_{0}\right)=0.03, \mathrm{u}\left(E_{\mathrm{Z}}\right)=0.2 \mathrm{~kJ} / \mathrm{mol}$, $\mathrm{u}(Q)=2.3 \mathrm{~kJ} / \mathrm{kg}$. 


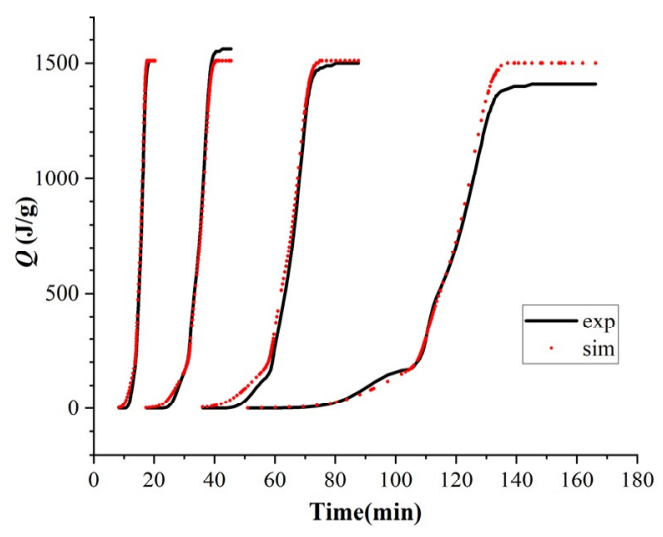

(a) Curve of heat release and time

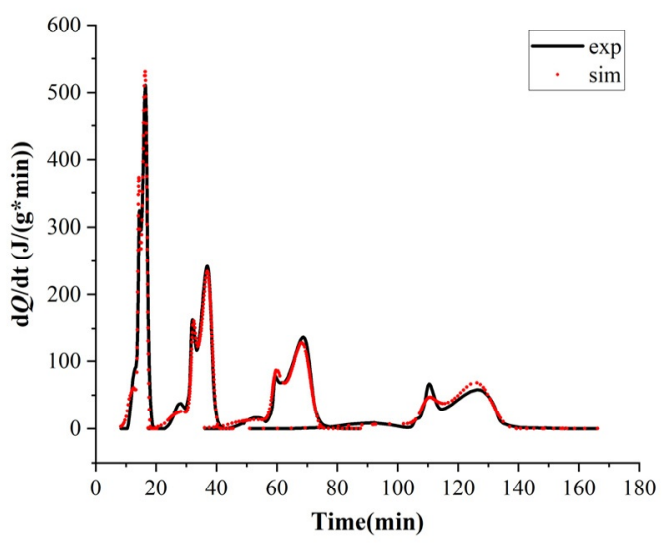

(b) Curve of heat release rate of $d Q / d t$ and time Figure.12. Simulation and experimental curve based on 4-step reaction model

\subsection{Calculation of TMRad}

The time to reach the maximum reaction rate under adiabatic conditions, called as $\mathrm{TMR}_{\mathrm{ad}}$, is an important indicator to evaluate the possibility of explosion in the system [24]. In addition, the temperature corresponding to $\mathrm{TMR}_{\mathrm{ad}}$ for $24 \mathrm{~h}$ is $T_{\mathrm{D} 24}$. In this section, the four-step continuous reaction kinetic model obtained by numerical simulation is used to predict $\mathrm{TMR}_{\mathrm{ad}}$, and the obtained prediction results have certain guiding significance for the process production of DINA.

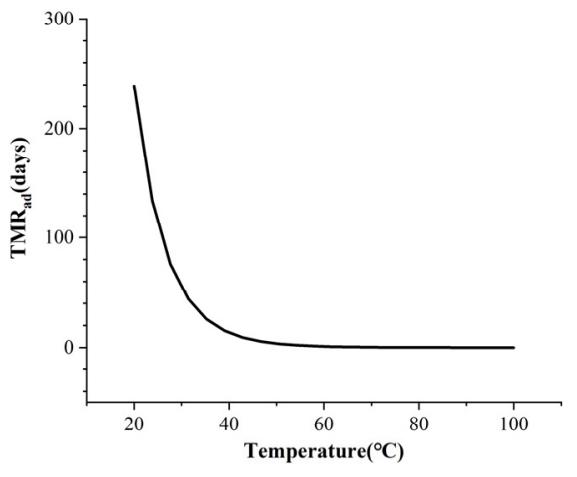

Figure.13 TMR $a$ ad DINA + 29\% DEA

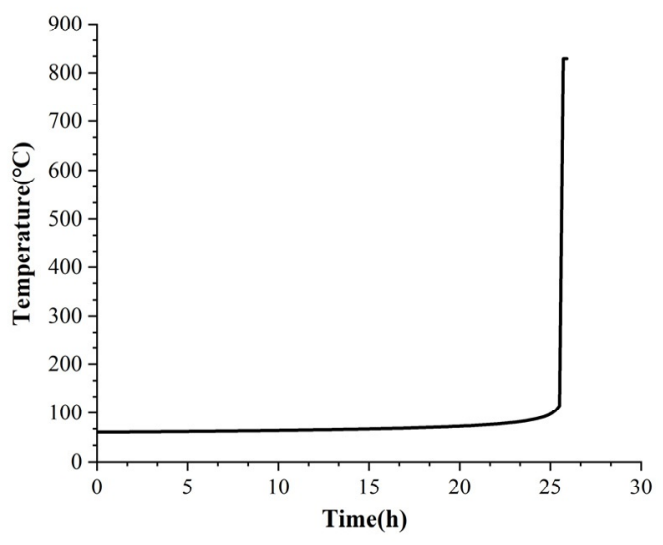

Figure. 14 Adiabatic runaway temperature prediction curve at $60^{\circ} \mathrm{C}$

It can be seen from Section 2.1 that the reaction temperature range of the nitric acid/magnesium oxide $\left(\mathrm{HNO}_{3} / \mathrm{MgO}\right)$ approach is $60^{\circ} \mathrm{C}-65^{\circ} \mathrm{C}$, if the target reaction encounters cooling failure or stirring failure, the system can be approximated as adiabatic conditions, in this case, the calculated value of $\mathrm{T}_{\mathrm{D} 24}$ as shown in Fig. 13 is $61^{\circ} \mathrm{C}$. The reaction system will reach the maximum reaction rate (exothermic rate) in 24 hours or less than 24 hours, even without considering the temperature rise caused by the accumulation of synthetic reaction materials, that is, the $\mathrm{TMR}_{\mathrm{ad}}$ of the actual process may be less than $24 \mathrm{~h}$. The adiabatic runaway process starting from $60^{\circ} \mathrm{C}$ (Fig.14) further confirmed the above conclusion. When the adiabatic onset temperature is $60^{\circ} \mathrm{C}$, the $\mathrm{TMR}_{\mathrm{ad}}$ is about 25.7 hours. In addition, one can see from the figure that the longer adiabatic indication time temperature of the system results in the self-acceleration that temperature rises instantaneously at the maximum reaction rate. Even if the temperature alarm is $10^{\circ} \mathrm{C}$ higher than the process temperature, the reserved safe operation time will be greatly shortened. Therefore, when the reaction system is in adiabatic state due to failure of stirring or failure of cooling, a large amount of accumulation of DEA should be avoided.

\section{Conclusion}

1) According to the dynamic DSC screening test results, when the content of DEA is $29 \%$, the onset temperature of the mixture of DINA and DEA is the lowest.

2) Based on isothermal experiment combined with "Interruption and re-scanning" method, it can be known that the exothermic peak 1 is a n-order reaction. Both exothermic peaks 2 and 3 are autocatalytic reactions. Exothermic peak 4 also has certain autocatalytic properties.

3) The relationship between the $E_{\alpha}$ and $\alpha$ obtained by the Friedman method indicates that the decomposition of DINA containing 29\% DEA is a multi-step reaction, and its activation energy fluctuates between $70 \mathrm{~kJ} / \mathrm{mol}$ and $170 \mathrm{~kJ} / \mathrm{mol}$. 
4) A four-step continuous reaction (n-order + autocatalytic + autocatalytic + autocatalytic) model was used to nonlinearly fit the dynamic DSC curve.

5) The relationship between $\mathrm{TMR}_{\mathrm{ad}}$ and temperature is predicted, and the $\mathrm{T}_{\mathrm{D} 24}$ of DINA containing $29 \%$ DEA is $61^{\circ} \mathrm{C}$, which means that there is a certain thermal safety hazard in the process of preparing DINA with the nitric acid/magnesium oxide $\left(\mathrm{HNO}_{3} / \mathrm{MgO}\right)$ approach.

\section{References}

1. H.S. Dong, F.F. Zhou. High-energy explosives and related properties. Science, Beijing,1989, pp.62-69.

2. J Neutz, O. Grosshardt, S. Schäufele, et al. Synthesis, Characterization and Thermal Behaviour of Guanidinium-5-aminotetrazolate (GA)-A New Nitrogen-Rich Compound, Propell. Explos. Pyrot, 28 (2010)

3. M. Hiskey, D. Chavez. Insensitive high-nitrogen compounds. NTIS No： DE220012776133,2001.

4. J. Zhou, L. Ding, X. Wang, et al. Transformation and Stability of $\mathrm{N}$-Nitrodiethanolamine Dinitrate Nitration Liquid System under Thermal and Mechanical Stimulation, Chemistry Open, 7 (2018)

5. W.F. Pi, X.D. Song, C. Zhang. Combustion performance of double-based propellant with a leadfree catalyst Gal-BiCu, J. Energ. Mater. 19 (2011).

6. Y.Y. Ma. Effect of DINA on the performance of double base propellant, J. Energ. Mater. 2 (1995).

7. A. Ksiczak, M. Ostrowski, W. Tomaszewski. Thermochemistry of the binary system nitrocellulose + N-nitrodiethanolamine dinitrate, J. Therm. Anal. Calorim, 94 (2008) 275-279.

8. M.A. Zayed, A.A. Soliman, M.A. Hassan. Evaluation of malonanilides as new stabilizers for double-base propellants, J. Hazard Mater. 73 (2000) 237-244.

9. J. Zhang. Thermal decomposition characteristic and kinetics of DINA, J. Therm. Anal. Calorim, 133 (2017) 1-9.

10. T.S. Ren. Chemistry and technology of nitramine and nitrate ester explosive, Weapon Industry, Beijing,1994, pp.325-340.

11. Z.C. Chen, J.K. Chen, X.X. Zhang. Technological Design of Contimaous Manufacture of DINA, J. Nanjing U SCI TECHNO: NAT SCI ED, 2 (1982).

12. J. Zhang, B.B. Xue, G.N. Rao, et al., Thermal decomposition characteristic and kinetics of DINA, J. Therm. Anal. Calorim. (2017).

13. J.M. Tseng, T.F. Hsieh, Y.M. Chang, Prediction of thermal hazard of liquid organic peroxides by nonisothermal and isothermal kinetic model of DSC tests, J. Therm. Anal. Calorim. 109 (2012).

14. J.R. Chen, S.Y. Cheng, M.H. Yuan, Hierarchical kinetic simulation for autocatalytic decomposition of cumene hydroperoxide at low temperatures, J. Therm. Anal. Calorim. 96 (2009).
15. X.R. Li, H. Koseki, SADT prediction of autocatalytic material using isothermal calorimetry analysis, Thermochim. Acta 431 (2005).

16. F. Stoessel, Thermal Safety of Chemical Processes, Wiley-VCH, Weinheim, 2008, pp.279-282.

17. O.J.R. Valdes, V.C. Moreno, S.P. Waldram, et al., Experimental sensitivity analysis of the runaway severity of dicumyl peroxide decomposition USING adiabatic calorimetry, Thermochim. Acta 617 (2005).

18. B. Roduit, M. Hartmanna, P. Follyb, et al., Parameters influencing the correct thermal safety evaluation of autocatalytic reaction, Chem. Eng. Trans. 31 (2013).

19. T. Yang, T, L.P. Chen, W.H. Chen. Experimental Method on Rapid Identification of Autocatalysis in Decomposition Reactions, Phys. Chem. Acta 30 (2014).

20. G.B. Lu, T. Yang, L.P. Chen. Thermal decomposition kinetics of 2-ethylhexyl nitrate under non-isothermal and isothermal conditions, J. Therm. Anal. Calorim, 124 (2016).

21. S. V yazovkin, A. K. Burnham, M. José, Criado, et al. ICTAC kinetics committee recommendations for performing kinetic computations on thermal analysis data, Thermochim. Acta 520 (2011).

22. A. Kossoy, T. Hofelich, Methodology and software for assessing reactivity ratings of chemical systems, Process. Saf. Prog. 22 (2003).

23. Thermal Safety Software(TSS), ChemInform Saint Petersburg(CISP) Co., Ltd. St. Petersburg, Russia, 2017.

24. J.H. Sun, H. Ding. Thermal hazard evaluation of chemicals. Science, Beijing,2007. 